\title{
CORRESPONDENCE
}

\section{Vitamin D therapy in adults with diabetes mellitus}

\author{
Gianluca Bardini, Ilaria Dicembrini, Mario Serio and Carlo Maria Rotella
}

We read with interest the News and Views article by Joanna Mitri and Anastassios G. Pittas (Shining a light: the role of vitamin D in diabetes mellitus Nat. Rev. Endocrinol. 6, 478-480;2010). ${ }^{1}$ We fully agree on the utility of vitamin $\mathrm{D}$ supplementation in diabetes mellitus; however, we have an important observation on the author conclusions, in particular, in the Practice point box, concerning the suggested doses of vitamin D supplementation, it should be considered an important clinical point. We suppose that the authors are suggesting a supplementation with 25-hydroxycholecalciferol because in our clinical experience the doses of a supplementation with 1,25-dihydroxycholecalciferol that we can use in clinical practice are much lower, ranging between $0.5 \mu \mathrm{g}$ to $1.5 \mu \mathrm{g}$ daily, at maximum. We think that this aspect should be pointed out to avoid important mistakes by physicians.

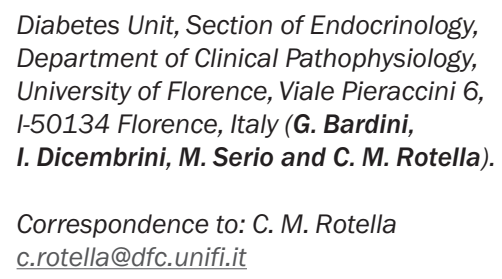

1. Mitri, J. \& Pittas, A. G. Shining a light: the role of vitamin D in diabetes mellitus Nat. Rev. Endocrinol. 6, 478-480 (2010). 